\title{
REQUISITOS DE AUTOCUIDADO DE MULHERES TRANSEXUAIS EM USO DE HORMÔNIOS SEXUAIS SEGUNDO TEORIA DE OREM*
}

\author{
Carla Andreia Alves de Andrade1, Andréa Roges Loureiro², Esmeraldo Rodrigues de Lima Neto \\ Eliane Maria Ribeiro de Vasconcelos ${ }^{4}$, Ednaldo Cavalcante de Araújo ${ }^{5}$
}

\begin{abstract}
RESUMO: Objetivo: identificar requisitos de autocuidado de mulheres transexuais em uso de hormônios sexuais, fundamentado na Teoria Geral de Orem. Método: estudo descritivo-exploratório com abordagem qualitativa, desenvolvido em Recife, capital de Pernambuco, de novembro de 2016 a fevereiro de 2017. A coleta de dados foi realizada por meio de entrevistas semiestruturadas, com uma amostra composta por 10 mulheres transexuais em uso de hormônios sexuais, selecionadas pela técnica Snowball. A análise foi realizada com o auxílio do Software IRAMUTE Q versão 0.7. Resultados: os requisitos encontrados foram: prevenção dos perigos à vida, funcionamento e bem-estar; busca e garantia de assistência médica apropriada; adaptação às modificações do corpo; modificação de autoimagem; e eventos adversos que afetam o desenvolvimento. Conclusão: os requisitos estiveram ancorados em questões geradas pelo baixo conhecimento sobre o uso de hormônios e pela baixa qualidade das informações recebidas por meio dos profissionais de saúde. DESCRITORES: Pessoas transgênero; Autocuidado; Hormônios; Feminino.
\end{abstract}

\section{SELFCARE REQUIREMENTS OF TRANSSEXUAL WOMEN USING SEX HORMONES, ACCORDING TO THE OREM SELFCARE THEORY}

ABSTRACT: Objective: to identify self-care needs of transsexual women using sex hormones, based in Orem's General Theory of Nursing. Method: descriptive-exploratory study with a qualitative approach, undertaken in Recife, capital of the Brazilian state of Pernambuco, between November 2016 and February 2017. Data collection was undertaken through semistructured interviews, with a sample of 10 transsexual women using sex hormones, selected using the Snowball technique. Analysis was undertaken using the IRAMUTE Q software, version 0.7. Results: the needs found were: prevention of danger to life, functioning and well-being; seeking and ensuring appropriate medical care; adapting to the changes in the body; modification of self-image; and adverse events affecting development. Conclusion: the requirements were anchored in issues caused by poor knowledge about the use of hormones, and by the poor quality of the information received through the health professionals.

DESCRIPTORS: Transgender persons; Selfcare; Hormones; Female.

\section{REQUISITOS DE AUTOCUIDADO DE MUJERES TRANSEXUALES QUE UTILIZAN HORMONAS SEXUALES DE ACUERDO A LA TEORÍA DE OREM}

RESUMO: Objetivo: identificar requisitos de autocuidado de mujeres transexuales que usan hormonas sexuales, por medio de la fundamentación de la Teoría General de Orem. Método: estudio descriptivo exploratorio con abordaje cualitativo, desarrollado en Recife, capital de Pernambuco, de noviembre de 2016 a febrero de 2017. Se recogieron los datos por medio de entrevistas semi estructuradas, con una muestra de 10 mujeres transexuales que utilizan hormonas sexuales, seleccionadas por la técnica Snowball. Se realizó el análisis con la ayuda del Software IRAMUTE Q versión 0.7. Resultados: Ios requisitos hallados fueron: prevención de riegos de muerte, funcionamiento y bienestar; búsqueda y garantía de asistencia médica apropiada; adaptación a los cambios del cuerpo; alteración de la autoimagen; y eventos adversos que afectan el desarrollo. Conclusión: los requisitos estuvieron basados en cuestiones generadas por poco conocimiento acerca del uso de hormonas y por la baja cualidad de las informaciones provenientes de los profesionales de salud.

DESCRIPTORES: Personas transgénero; Autocuidado; Hormonas; Femenino.

\footnotetext{
*Artigo extraído da dissertação de mestrado intitulado: Autocuidado de mulheres transexuais em uso de hormônios sexuais a Luz da Teoria de Orem. Universidade Federal de Pernambuco, 2017.

${ }^{1}$ Enfermeira. Mestre em Enfermagem pela Universidade Federal de Pernambuco. Recife, PE, Brasil.

EEnfermeira. Doutoranda do Programa de Pós-Graduação em Enfermagem da Universidade Federal de Pernambuco. Recife, PE, Brasil.

${ }^{3}$ Enfermeiro. Especialista em Enfermagem do trabalho. Recife, PE, Brasil.

${ }^{4}$ Enfermeira. Doutora em Enfermagem. Professora Adjunta da Universidade Federal de Pernambuco. Recife, PE, Brasil.

${ }^{5}$ Enfermeiro. Doutor em Enfermagem. Professor Adjunto da Universidade Federal de Pernambuco. Recife, PE, Brasil.
} 


\section{INTRODUÇÃO}

Por intermédio do Programa governamental "Brasil sem Homofobia", a população de Lésbicas, Gays, Bissexuais, Travestis e Transexuais (LGBT) obteve o reconhecimento da própria complexidade em relação à saúde, a partir da inserção de práticas e políticas de saúde voltada às especificidades dos seus integrantes. A Política Nacional de Saúde LGBT constitui um documento norteador e legitimador das necessidades e das especificidades de pessoas LGBT, pois está em conformidade com a Constituição Federal de 1988 e a Carta de Usuários do Sistema Único de Saúde, publicada pelo Ministério da Saúde, que explicita os direitos e deveres dos usuários ${ }^{(1-3)}$.

Pessoas transgêneros passam por agravos à saúde bem mais complexos e por demandas ainda mais elevadas, ${ }^{(2-3)}$ que envolvem as questões de gênero e de identidade de gênero decorrentes da discriminação e do preconceito, pelo impacto social e psicológico que eles causam na vida das pessoas, sobretudo, porque o estigma e a discriminação seguem entre os principais obstáculos para o acesso à saúde de pessoas que não se sentem nos padrões heteronormativos apregoados pela sociedade ${ }^{(3)}$.

Para se entender a transexualidade, é importante compreender que o sexo biológico e as características físicas não determinam a identidade de gênero do indivíduo ou a autopercepção que ele tem de si, ${ }^{(4)}$ portanto, existe a necessidade dos familiares e dos profissionais de saúde respeitarem tais indivíduos e acolhê-los para que o sofrimento diante do conflito estabelecido pelos padrões da sociedade e do sentido comum sejam amenizados até o estabelecimento pleno da sua identidade ${ }^{(5)}$.

No processo de construção das identidades trans e principalmente em relação às mulheres transexuais deve-se levar em consideração um fator importante: na maioria das vezes, o uso de hormônios sexuais não ocorre com acompanhamento nos serviços de atenção básica à saúde, porém, tal uso se configura aspecto preponderante quando essas mulheres decidem se transformar, pois é no corpo que elas localizam os símbolos do que possui caráter masculino e feminino ${ }^{(6-9)}$.

O início indiscriminado e inadequado dos hormônios sexuais ocorre, muitas vezes, na adolescência, por volta dos 14 aos 15 anos, empiricamente com a ingestão ou aplicação de medicamentos com progesterona e/ou estrogênio associados, ${ }^{(7,9)}$ o que acaba por aumentar o risco de doenças coronarianas, acidente vascular cerebral e fenômenos tromboembólicos ${ }^{(8)}$.

A utilização de uma teoria de enfermagem na prática de Autocuidados (AC) em transexuais femininas faz-se importante por proporcionar maior comunicação terapêutica entre a enfermagem e a paciente, ao se adequar à problemática de cada indivíduo.

A Teoria Geral de Orem é constituída por três constructos teóricos inter-relacionados: a Teoria do Autocuidado (TAC), a Teoria dos Déficits de Autocuidado e a Teoria de Sistema de Enfermagem. A teoria que fundamentou este estudo foi a Teoria do Autocuidado (TAC). No entanto, para se entender esta teoria, é importante compreender os conceitos das atividades de AC que demonstram a capacidade do ser humano em engajar-se no AC; o das exigências terapêuticas que são as ações de $A C$ a serem desempenhadas com alguma duração para preencher exigências conhecidas de AC; e o conceito dos requisitos para o $\mathrm{AC}_{,}{ }^{(10-14)}$ que foi o constructo da TAC utilizado no estudo.

Quanto ao conceito dos requisitos de AC, para que houvesse uma melhor compreensão, eles foram divididos em três categorias. Primeiro, os Universais correspondentes aos requisitos associados ao processo de vida e de manutenção da integridade estrutural e funcionante dos seres humanos. Os conceitos de Desenvolvimento que envolvem as expressões especializadas de requisitos Universais de $A C$, os quais foram particularizados por processos de desenvolvimento ou derivados de uma nova condição. Por fim, há os requisitos de desvios de saúde que são exigidos quando há presença de doença, algum ferimento ou também em consequência de medidas médicas para diagnosticar ou corrigir uma condição existente $\mathrm{e}^{(10,12-15)}$.

A realização do estudo justifica-se pela importância de conhecer os requisitos do AC de mulheres transexuais em uso de hormônios sexuais, sem o acompanhamento multiprofissional, de forma a subsidiar o enfermeiro na promoção de ações educativas, com objetivo de desenvolver competências e habilidades para o AC deste público. Desta forma, o presente estudo visa identificar os requisitos de AC de mulheres transexuais em uso de hormônios sexuais. 


\section{METODOLOGIA}

Estudo descritivo, exploratório, de abordagem qualitativa, desenvolvido na cidade de Recife, capital de Pernambuco, Brasil, que segundo os dados do Instituto Brasileiro de Geografia e Estatística (IBGE) de 2010, possuía em média 1.537.704 habitantes, ${ }^{(16)}$ porém, não foi identificado o quantitativo da população transexual devido às subnotificações e ao alto grau de invisibilidade deste segmento populacional.

Devido à caracterização da amostra, optou-se pela amostragem do tipo Snowball sampling (bola de neve) que se caracteriza por utilizar a indicação de um membro da população estudada a partir de outro que faça parte da mesma ${ }^{(17)}$.

Uma vez que os termos mulheres transexuais, mulheres trans, travestis e male-to-female (MTF) são utilizados,algumas vezes, com concepções diferenciadas para designar a população transgênero, foi definido que "mulheres transexuais" seria o termo empregado entre os que já são usados para o mesmo objeto de estudo, ou seja, para as pessoas que se definissem e se identificassem como mulher, por ser uma forma de legitimar a sua existência social e a construção da identidade de gênero singular.

Para compor a amostra, as mulheres transexuais deveriam ter feito ou estarem, no momento, em uso de hormônios sexuais sem acompanhamento multidisciplinar, serem maiores de 18 anos e ainda residirem na cidade de Recife. Mesmo com ocorrência de indicação, foram excluídas as participantes que se afastaram de Recife e/ou não responderam aos contatos realizados durante o período das entrevistas.

A coleta de dados foi realizada durante os meses de novembro de 2016 e fevereiro de 2017. A indicação ocorreu a partir da "semente", que indicou participantes da Articulação e Movimento para Travestis e Transexuais de Pernambuco (AMOTRANS) e da Nova Associação de Travestis e Transexuais de Pernambuco (NATRAPE) que compuseram os indivíduos "onda", em que cada entrevistada fez novas indicações de integrantes de novas "ondas" posteriores. Conforme se encontra esquematizado na Figura 1 como ocorreu a formação das ondas.

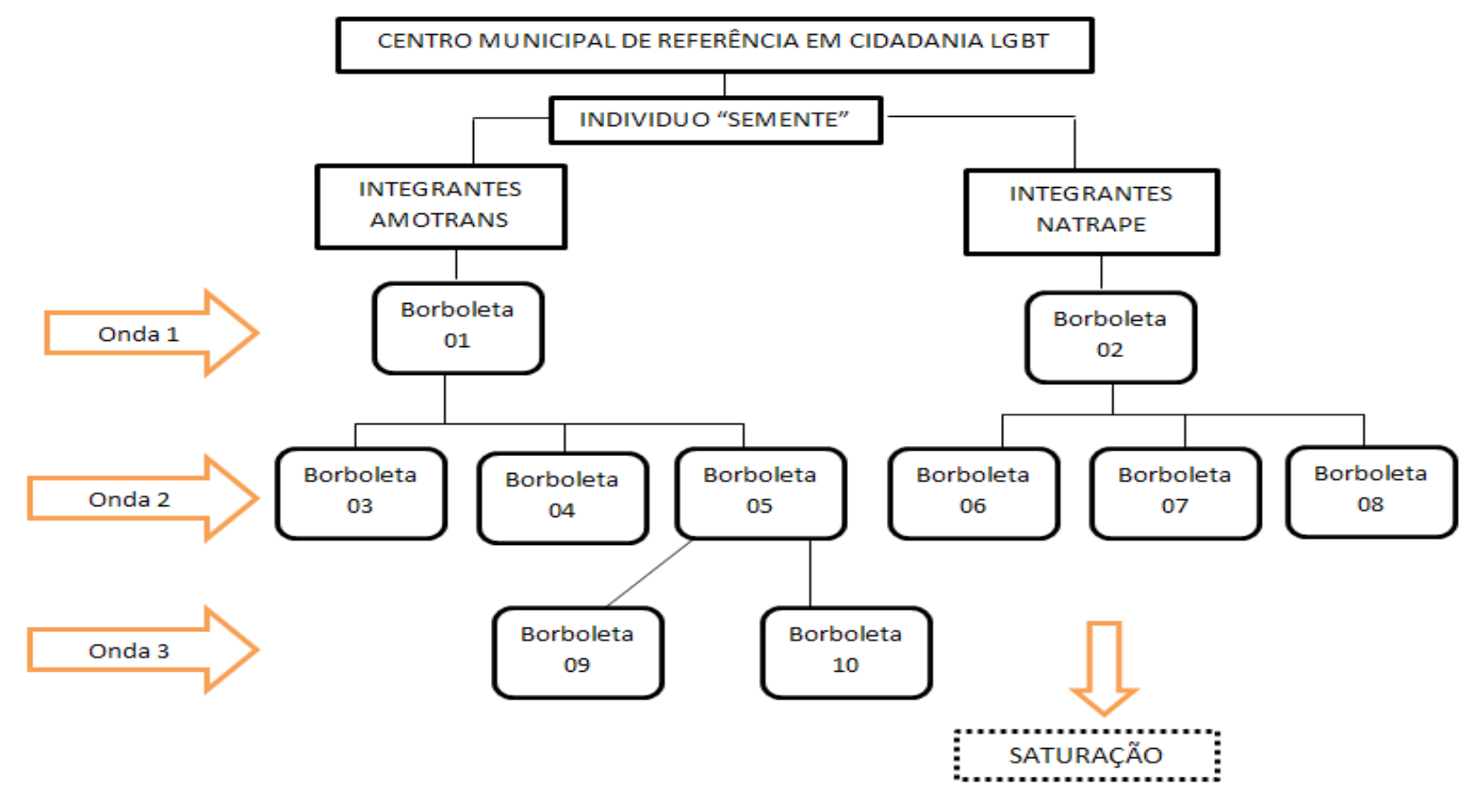

Figura 1 - Fluxograma da Técnica Snowball. Recife, PE, Brasil, 2017

Para a entrevista, foi utilizado um questionário semiestruturado com questões sobre quais ações de AC são realizadas pelas mulheres transexuais em uso de hormônio sexuais. As gravações foram realizadas a partir de aplicativos de gravação de áudio em arquivo MP3, para dispositivos de Smartphone e/ou tablete com duração de 30 a 40 minutos, e as transcrições feitas no mesmo dia ou no dia seguinte, com 
o intuito de recordar detalhes sutis da entrevista.

As transcrições foram lidas e validadas pelas participantes em encontros posteriores. A análise foi realizada com o auxilio do software Interface IRAMUTEQ (Interface de $R$ pour les Analyses Multidimensionnelles de Textes Et de Questionnaires), software gratuito e desenvolvido sob a lógica da open source, licenciado por GNU GPL. O programa viabiliza diferentes tipos de análises textuais, organiza a distribuição do vocabulário de forma compreensível e visualmente clara ${ }^{(18)}$.

Os dados do estudo foram analisados em relação ao constructo dos requisitos de AC da TAC em conformidade com a Classificação Hierárquica Descendente (CHD). Ou seja, a partir da relação entre as classes semânticas, foram atribuídosos respectivos sentidos e valores em classes temáticas e categorias, sendo ilustrados em um dendograma constituídos por segmentos de textos classificados conforme os vocábulos e elucidados em relação entre as classes $^{(18)}$.

Os sujeitos foram identificados pela palavra Borboleta (o termo borboleta apresenta relação com o público, devido ao processo de metamorfose, fato apontado devido à semelhança com o processo de readequação do corpo do/da transexual), seguidos de um numero (B1... B10) correspondente às falas das entrevistadas.

O estudo foi realizado após a aprovação do projeto de pesquisa pelo Comitê de Ética em Pesquisa (CEP) do Centro de Ciências da Saúde da Universidade Federal de Pernambuco (CCS/UFPE), com o Certificado de Apresentação para Apreciação Ética (CAEE) 56903416.3.0000.5208 e Parecer de aprovação n. 1.707.429, em consonância com a Resolução 466/12, do Conselho Nacional de Saúde.

\section{RESULTADOS}

Participaram do estudo 10 mulheres transexuais que pertenciam às seguintes faixas etárias: duas com 22 a 23 anos; quatro com 25 a 26 anos; uma tinha 29 anos e três participantes tinham de 36 a 40 anos. Quanto à escolaridade, duas tinham ensino fundamental completo; cinco tinham ensino médio completo e uma incompleto; duas tinham ensino superior incompleto. Quanto à ocupação, apresentouse de maneira diversificada (artista plástica, call Center, esteticista, estudante, cabeleireira, profissional do sexo, recepcionista), porém, apenas três com vínculo empregatício. Em relação a possuírem relacionamento estável, apenas uma declarou ser casada.

O software analisa o corpus, em que cada entrevista corresponde a uma unidade de contexto inicial $(\mathrm{UCI})$, nas quais cada trecho corresponde a uma unidade de contexto elementar (UCE). Desse modo, o corpus foi composto por $10 \mathrm{UCl}$ e 315 UCE que continham 1.739 formas distintas, com ocorrência de 11.243 vezes, o que representou $100 \%$ das entrevistas analisadas.

Para a formulação das classes, foram considerados 239 UCE, o que correspondeu a 75,87\% de aproveitamento. Deste número de palavras diferentes, o software analisou a importância de cada uma e forneceu a frequência mínima ou superior igual a três. Após isso, prosseguiu-se com a quantificação destas palavras e foi elaborado o dendograma com as classes em função de seus vocábulos.

O dendograma foi lido de acordo com as partições ocorridas. Houve a $1^{a}$ partição ou interação em dois subcorpus, separando as classes 1 e 2 do restante do material. Em um segundo momento, o subcorpus maior foi dividido e deu origemà classe 3 (2 $2^{a}$ partição ou interação). No terceiro momento, uma nova partição originou as classes 4 e 5 . A CHD parou, pois as 5 classes mostraram-se estáveis, ou seja, composta de UCE com vocabulário semelhante. A distribuição das palavras por classes pode ser visualizada na Figura 2. 


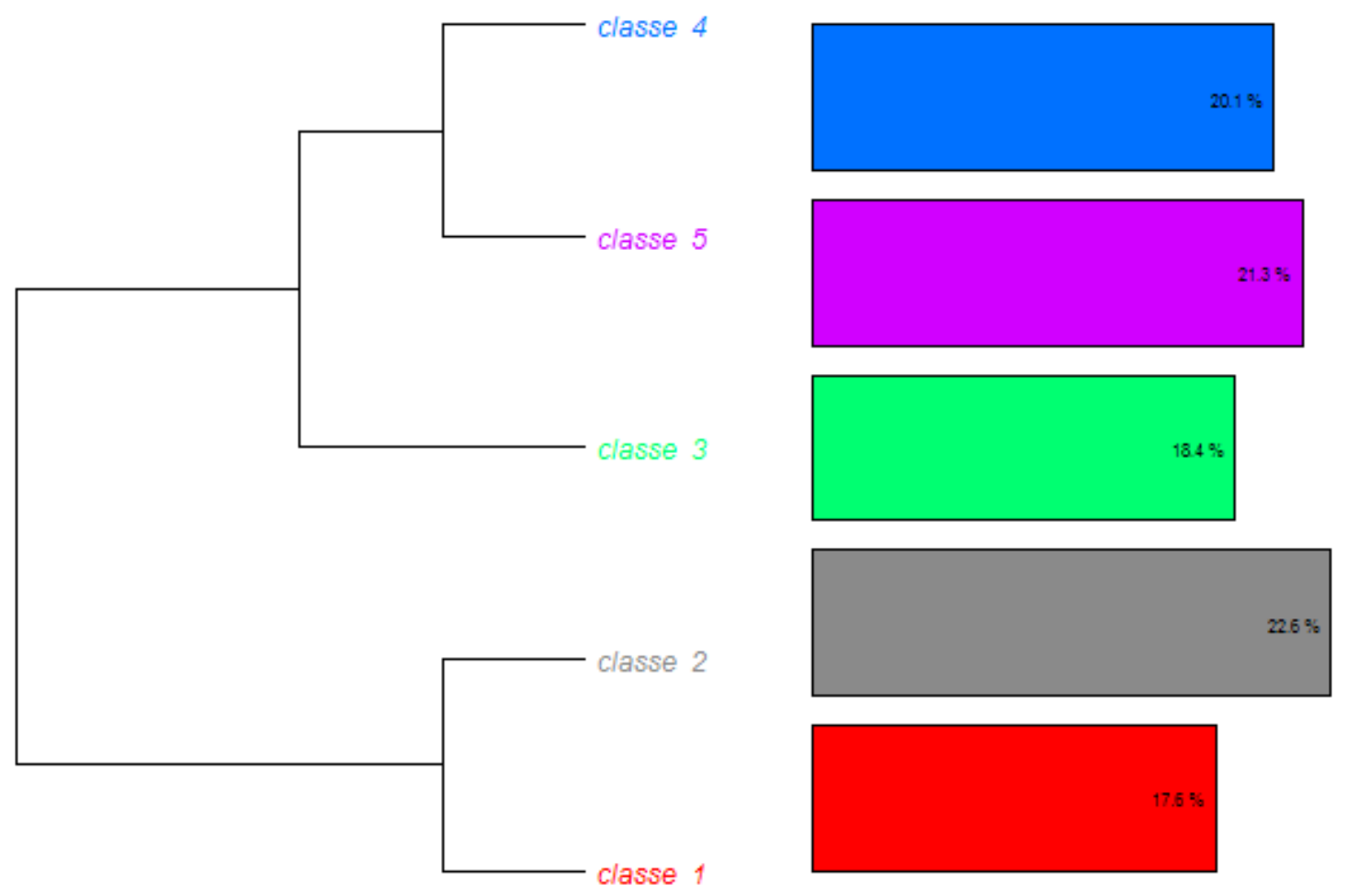

Figura 2 - Dendograma representativo das repartições em classes, percentagem das palavras que se destacaram nos estudos sobre uso de hormônios em mulheres transexuais. Recife, PE, Brasil, 2017

A titulação das categorias foi submetidaà análise qualitativa, conforme o conteúdo que elas retratam. Neste sentido, para análise e discussão das categorias formadas pelas respectivas classes foram nomeadas, apresentadas e discutidas de acordocom o significado das mesmas.

Identificaram-se, inicialmente, os três eixos temáticos (Figura 2) que foram categorizados de acordo com o constructo da Teoria de AC (requisitos de AC). No Quadro 1, encontram-se organizadosos eixos, as categorias, as classes e requisitos de $\mathrm{AC}$ encontrados com maior predominância nas narrativas analisadas.

Quadro 1 - Distribuição dos eixos com classes e seus respectivos requisitos de AC. Recife, PE, Brasil, 2017

\begin{tabular}{|c|c|c|c|}
\hline EIXOS & $\begin{array}{l}\text { Categoria de } \\
\text { Requisito }\end{array}$ & Classes & Requisito de AC \\
\hline Primeiro & Desvio de Saúde & $\begin{array}{l}\text { Dois } \\
\text { Um }\end{array}$ & $\begin{array}{l}\text { Modificações de Autoimagem } \\
\text { Busca e garantia de assistência médica apropriada }\end{array}$ \\
\hline $\begin{array}{l}\text { Segundo } \\
\text { Terceiro }\end{array}$ & $\begin{array}{l}\text { Universal } \\
\text { Desenvolvimento }\end{array}$ & $\begin{array}{l}\text { Três } \\
\text { Cinco } \\
\text { Quatro }\end{array}$ & $\begin{array}{l}\text { Prevenção dos perigos à vida, funcionamento bem-estar. } \\
\text { Adaptação às modificações do corpo } \\
\text { Eventos adversos que podem afetar o desenvolvimento }\end{array}$ \\
\hline
\end{tabular}

\section{Primeiro eixo}

Nomeado de "Requisitos de desvio de saúde", dele emergiram as classes 1 e 2 . Na classe 2, constituída por 54 segmentos de texto $(22,6 \%)$, predominou o requisito modificação de autoimagem compreendida pelos vocabulários mais frequentes e significativos: bloqueador, viver, masculino, feminino, prender, travesti, autoimagem, espelho, precisar, realizar, aparência e morrer. 
O que a gente preserva é isso: a autoestima. Se sentir bem com agente mesma, passar pela outra travesti ou mulher trans e a outra me ver belíssima, porque vivemos das opiniões alheias e dos olhares. (Borboleta 1)

Não se tem felicidade sem hormônios, porque a aparência é tudo para se sentir e estar lá em cima. Ficamos todas doidas querendo que os homens olhem pra gente estando bem feminina. (Borboleta 4)

Na classe 1, constituída por 42 segmentos de texto $(17,6 \%)$, houve o predomínio do requisito busca e garantia de assistência médica apropriada, sendo compreendida pelos vocabulários mais frequentes e significativos: atender, transexual, questões, população, hospital, maltratar, infelizmente, ambulatório, atendimento, saúde, relação e nome social.

No posto eu não vou, não. E mesmo se fosse não ia ser atendida, porque dizem que a gente não tem útero pra pegar anticoncepcional. Praticamente todas as meninas trans se queixam do atendimento quando vão ao posto. (Borboleta 5)

Não queremos saber sobre os riscos e nem sabemos sobre cuidados, nós queremos saber do que estamos vendo no espelho. Tudo que for matar a aparência masculina, aquilo que nos incomoda, a gente segue a risca. A saúde fica esquecida em compensação do corpo, porque nós não temos o hábito de ir ao posto de saúde, porque sempre somos maltratadas. (Borboleta1)

\section{Segundo eixo}

Foi nomeada a categoria como "Requisito Universal", proveniente da classe 3, com a demanda do requisito de AC Universal - prevenção dos perigos à vida, funcionamento e bem-estar - constituída por 44 segmentos de texto $(18,4 \%)$, compreendida pelos vocabulários mais frequentes e significativos: reação, sensível, demasia, perder, cuidado, diminuir, conhecer, beber, frigidez, chá, alimentação e fumar.

Minhas amigas indicavam o cuidado de tomar chás, sempre tomar vitamina $C$, cuidar da alimentação, comer menos frituras, não beber ou fumar. Porém, é tudo avulso, é igual a receita da vovó, sempre tem uma que diz alguma coisa. Então, uma vai pegando uma pra outra. É uma corrente, uma rede. (Borboleta 6)

\section{Terceiro eixo}

Nomeou-se esta categoria de "Requisitos de Desenvolvimentos", a qual foi composta pelas classes 5 e 4. Na classe 5 desta categoria predominou o requisito adaptação às modificações do corpo, constituída por 51 segmentos de texto $(21,3 \%)$ do corpus textual, compreendida pelos vocabulários mais frequentes e significativos: começar, amiga, escutar, pedir, aplicar, através, continuar, hormônios, injetável, comprimido.

É um jogo de quebra cabeça a vida da gente, porquetem de batalhar pra ficar completa, tem de fazer peitos, bunda, perna, tem de se sentir completa. Mas não pode deixar de tomar hormônios, nunca deixa. Todas tomam, apenas algumas não tomam mais como tomavam antigamente. A gente não quer saber de risco. Isso é um vício, uma droga na nossa vida. (Borboleta 3)

A demanda do requisito eventos adversos que podem afetar o desenvolvimento esteve presente na classe 4 desta categoria e foi constituída por 48 segmentos de texto, com (20,1\%) do corpus textual. Logo, esta classe foi compreendida pelos vocabulários mais frequentes e significativos: náuseas, cartela, tontura, resultado, afinar, comprar, rápido, crescer e sentir.

Eles mexem com o psicológico. Você, às vezes, fica com vontade de chorar. Outro dia acorda e já esta alegre, variando assim. Tem horas que, de momento, você varia, mas tem horas que você está para baixo, mesmo. (Borboleta2)

Até hoje quando tomo, eu sinto como se estivesse numa TPM: você fica irritada e eu choro por qualquer coisa. Eu tinha medo porque eu achava que ia prejudicar muito a saúde, porém, eu perdi o medo quando eu vi que o meu corpo estava mudando. (Borboleta 8) 
A Teoria do Autocuidado (TAC) engloba, em si, os conceitos de AC, a atividade de AC, a exigência terapêutica de $\mathrm{AC}$ e os requisitos de AC. A capacidade de autocuidado não é, por ela mesma, um meio para manter, restabelecer ou melhorar a saúde e o bem-estar, mas uma expressão de uma potencialidade para a compreensão das condições e as limitações da ação das pessoas, que podem vir a se beneficiar com os cuidados de enfermagem. Observa-se então, a partir dos eixos identificados e as respectivas categorias, as expressões registradas, diante do conhecimentodos referidos requisitos sobre as ações de $\mathrm{AC}^{(19)}$.

\section{Primeiro eixo - Categoria Requisitos de Desvio de Saúde}

Quando há presença de doença, algum ferimento ou também em consequência de medidas médicas para diagnosticar ou corrigir uma condição existente, os requisitos de desvio de saúde são exigidos e podem ser entendidos enquanto ações para a preservação da saúde e podem ser evidenciados por modificações na estrutura e/ou funcionamento físico do indivíduo ${ }^{(12)}$.

O requisito "modificação de autoimagem" da Classe 2 do primeiro eixo demonstra a importância para a manutenção do bem-estar, da saúde, do relacionamento interpessoal, ao proporcionar melhor qualidade de vida às mulheres transexuais. A preocupação é expressa na construção do corpo feminino, portanto, tal requisito deve ser estimulado não somente para promoção da saúde, mas também para resgatar a autoestima, pois a mesma é atributo relevante e almejado, uma vez que as modificações produzidas na autoimagem corroboram com a diferenciada percepção do conceito de saúde X corpo saudável que todas almejam.

Quando a autoestima das mulheres transexuais encontra-se elevada, as mesmas sentem-se mais dispostas, mais capazes, inclusive, de realizar atividades cotidianas. A autoestima consiste na avaliação global que a pessoa faz do próprio valor e manifesta-se pela aceitação de si enquanto pessoa e por sentimentos de valor pessoal ${ }^{(20)}$.

A autoimagem pode ser compreendida como a representação mental do corpo, que será influenciada pelo meio em que o individuo vive. Envolve aspectos subjetivos e perceptivos, na forma pela qual a pessoa percebe o próprio corpo, situação que é encontrada entre o público transexual devido ao processo de incongruência em relação à genitália e ao gênero que lhe foi conferido ao nascer ${ }^{(5,9,20)}$.

Quanto ao requisito "busca e garantia de assistência médica apropriada" da Classe 1, o que limita atuações efetivas deste requisito às pacientes transexuaisé o fato de que os serviços de saúde ainda centralizamos atendimentos para clientes heterossexuais. As ações realizadas ainda estão distantes de desenvolverem atenção à saúde de forma integralizada ao público transexual com respeito às especificidades do mesmo.

Nas Unidades Básicas de Saúde (UBS) os programas mais difundidos centram-se nas crianças e gestantes, que abordam o sexo feminino, apenas na fase reprodutiva. Se for, portanto, analisar o caso das mulheres transexuais a exclusão é evidente, pois além de haver dificuldade de engajamento delas nos serviços dos programas, diante da cultura médica com uma visão voltada ao modelo biologicista, não se dissocia gênero de sexo.

O público transexual ainda encontra dificuldade e despreparo dos profissionais nos cuidados e orientações prestados, com importantes entraves encontrados desde o acolhimento, quando, por exemplo, em algumas UBS, rotineiramente o nome social sequer é respeitado ${ }^{(21-22)}$.

Segundo eixo - Categoria Requisitos Universais

Medidas que possam diminuir os agravos ou complicações devido ao uso dos hormônios são realizadas pelas mulheres transexuais ainda que de forma empírica. 
A demanda do requisito "prevenção dos perigos à vida, funcionamento e bem-estar" esteve presente por ser um aspecto realizado e buscado mesmo que de forma ainda insuficiente devido aos entraves de as ações serem realizadas de forma empírica, das informações serem repassadas e multiplicadas por outras mulheres sem o conhecimento científico, sem o acompanhamento e as orientações adequadas de profissionais de saúde e por, ainda, reforçarem conceitos arraigados dentro da construção de práticas do AC desempenhada pelo público estudado.

Compreender os significados que mulheres transexuais atribuem ao processo de hormonização, os autocuidados realizados, conhecer os motivos que as fazem passar por algo doloroso e arriscado, constituem-se como objetivos relevantes para se construir orientações voltadas para medidas corretas e adequadas de AC Universais, visto que a essência do AC é o autocontrole, a liberdade, a responsabilidade do indivíduo na busca pela melhoria de sua qualidade de vida ${ }^{(19-20)}$.

Os corpos transexuais sempre estão prontos para experimentarem diferentes possibilidades de mudanças, por serem verdadeiros lócus de subjetividade e produção de sentidos, assim, estão em construções e remodelações constantes. Os discursos remetem projetos de felicidades, mas, muitas vezes, produzem agravos à saúde e deformidades corporais, muitas vezes irreversíveis, ${ }^{(23-24)}$ o que torna importante o conhecimento das práticas positivas e adequadas do emprego da Teoria de AC de Orem para prevenir tais agravos e promover a manutenção do bem-estar físico e mental.

\section{Terceiro eixo - Categoria Requisitos de Desenvolvimento}

O requisito "eventos adversos que podem afetar o desenvolvimento" esteve presente na Classe 5, porém, mesmo quando tal requisito é reconhecido, não se torna empecilho para a continuidade do uso empírico dos hormônios pelas mulheres transexuais, uma vez que a percepção de saúde perpassa pelo reconhecimento da presença das características femininas neste corpo em construção.

Por se tratar de indivíduos em situação de vida peculiar, em que há necessidades distintas durante a automedicação, como o uso de hormônios, para obter um corpo com delineamento feminino, desenvolvido desta fase da vida delas, este requisito não tem a ver apenas com alterações de saúde, mas também com experiências pessoais ${ }^{(12,14)}$.

Em sua teoria, Orem mostra que o AC é uma função humana reguladora que os indivíduos têm de desempenhar por si só ou que alguém o execute para o mesmo ${ }^{(19-20)}$. Assim, demandas do requisito "eventos adversos que podem afetar o desenvolvimento" mostraram que na população transexual este requisito atua no aspecto regulador e mantenedor, uma vez que é a partir da construção do corpo feminino que as mulheres transexuais encontram-se inseridas aos grupos sociais dos quais fazem parte. $\mathrm{Na}$ teoria de AC, afirma-se que o individuo é livre para acertar, aprender, utilizar ou rejeitar o que lhe é oferecido, e pode ainda pedir ajuda para obter informações sobre o que deseja ${ }^{(12,19-20)}$.

O universo transexual torna-se denso, com inúmeras questões que precisam ser dialogadas e estudadas e, no que concerne ao campo do AC, mostra-se ainda muito insipiente. Com a finalidade de conquistar o corpo almejado, mulheres transexuais põem as próprias vidas em risco, a partir de procedimentos clandestinos, sem que haja um mínimo de segurança e/ou confiabilidade técnica.

Torna-se importante investir em abordagens compreensíveis e adaptadas à realidade, à cultura, à singularidade, aos limites, e às fraquezas de mulheres transexuais. Muitas vezes, os profissionais de saúde não conseguem identificar esses aspectos, e, nem sempre, possuem formação para promover a ampliação desta autonomia.

A principal limitação deste estudo foi o fato do grau de invisibilidade da população estudada ser tão grande, que não há censos do IBGE, e por ainda serem poucos os estudos que possam mapear tal segmento excluído, foi importante o inicio de a amostra ter sido a partir do individuo "semente" nas indicações na formação das "ondas" da amostra, mesmo com todas as limitações. 


\section{CONCLUSÃO}

Nesse estudo, percebeu-se que o desenvolvimento do AC pelas mulheres transexuais foi alterado pelas limitações impostas pelo conhecimento limitado das práticas de AC, que devem ser empregadas nas atividades de vida diária. Muitas delas, por exemplo, desconhecem o risco de fazer uso de álcool, tabaco ou se automedicar, concomitantemente ao uso de hormônios, logo tais limitações expõem esses indivíduos a perigo constante.

O presente estudo oferece possibilidades para compreender o contexto das práticas de AC realizadas empiricamente por mulheres transexuais, pois é possível identificar ações de AC com seus requisitos. Pode-se, assim, tomar atitudes mais direcionadas aos seus respectivos déficits na realização destas atividades de $A C$, viabilizando, desta forma, medidas mais direcionadas para realização de atividades de AC. Nos requisitos de AC prevalece o saber popular. As mulheres transexuais vivenciam déficits de AC no intuito de resguardar o direito de expressar saúde de acordo com as próprias concepções do que venha a ser um "corpo saudável". Constitui um desafio aos profissionais de saúde, com ênfase no papel do enfermeiro, ser capaz de agregar competências éticas, científicas e emocionais para estabelecer assistência inclusiva e acolhedora à população transexual em toda rede de saúde, de modo a resguardar o principio da saúde enquanto direito.

\section{REFERÊNCIAS}

1. Lionço T. Que direito à saúde para a população GLBT? Considerando direitos humanos, sexuais e reprodutivos em busca da integralidade e da equidade. Saúde Soc. [Internet] 2008;17(2) [acesso em 15 mai 2017]. Disponível: http:// dx.doi.org/10.1590/S0104-12902008000200003.

2. Cardoso MR, Ferro LF. Saúde e população LGBT: Demandas e especificidades em questão. Psicol. cienc. prof. [Internet] 2012;32(3) [acesso em 20 mar 2017]. Disponível: http://dx.doi.org/10.1590/S1414-98932012000300003.

3. Ministério da Saúde (BR). Secretaria de Gestão Estratégica e Participativa. Departamento de Apoio à Gestão Participativa. Política Nacional de Saúde Integral das Lésbicas, Gays, Bissexuais, Travestis e Transexuais. Brasília, DF: Ministério da Saúde; 2013.

4. Picazio C, editor. Sexo secreto: temas polêmicos da sexualidade. São Paulo: GLS; 1999.

5. Sampaio LLP, Coelho MTAD. Transexualidade: aspectos psicológicos e novas demandas ao setor saúde. Interface. [Internet] 2012;16(42):637-49. [acesso em 20dez 2016]. Disponível: http://dx.doi.org/10.1590/S1414-32832012000300005.

6. Bento B. A reinvenção do corpo: sexualidade e gênero na experiência transexual. $2^{\mathfrak{a}}$ ed. Natal: EDUFRN; 2014.

7. Spizzirri G, Azevedo RN, Abdo CHN. Travestismo de duplo sentido ou bivalente: considerações gerais. Diagn. Tratamento. [Internet] 2011;16(1):29-32. [acesso em 20 dez 2016]. Disponível: http://files.bvs.br/upload/S/1413-9979/2011/ v16n1/a1845.pdf.

8. Bruns MAT, Pinto MJC. Vivência transexual: o corpo desvela seu drama. Campinas: Átomo; 2003.

9. Benedetti MR. Toda feita: o corpo e o gênero das travestis. Rio de Janeiro: Garamond; 2005.

10. Garcia TR, da Nóbrega MML. Contribuição das teorias de enfermagem para a construção do conhecimento da área. Rev. Bras. Enferm. [Internet] 2004;57(2):228-32. [acesso em 15 mai 2017]. Disponível:http://dx.doi.org/10.1590/S003471672004000200019 .

11. dos Santos I, Sarat CNF. Modalidade da aplicação da Teoria do autocuidado de Orem em comunicações cientificas de enfermagem brasileira. Rev. Enferm. UERJ. [Internet] 2008;16(3):313-18 [acesso em 15 mai 2017]. Disponível: http:// www.facenf.uerj.br/v16n3/v16n3a03.pdf. 
12. Orem D. Nursing concepts of practice, 6th ed. St. Louis: Mosby; 2001.

13. George JB, organizador. Teorias de enfermagem: fundamentos para a prática profissional. 4ª ed. Porto Alegre: Artes Médicas; 2000.

14. Hartweg Donna L. Dorothea Orem: self-care deficit theory. Spring Publishing Company; 1991. (Notes on nursing theories; 4)

15. Leopardi MT, editor. Teoria e método em assistência de enfermagem. 2ª ed. Florianópolis: Soldasoft; 2006.

16. Instituto Brasileiro de Geografia e Estatística (IBGE). Ministério do Planejamento, Orçamento e Gestão. Sinopse do Censo Demográfico 2010 - Pernambuco. [Internet] Rio de Janeiro: IBGE; 2014 [Acesso em 26 jan 2017]. Disponível: http://www.censo2010.ibge.gov.br/sinopse/index.php?uf= 26\&dados=0.

17. Dewes JO. Amostragem em bola de neve e respondent-drive sampling: uma descrição dos métodos [dissertação]. Rio Grande do Sul (RS): Universidade Federal do Rio Grande do Sul; 2013. Disponível: http://hdl.handle.net/10183/93246.

18. Camargo BV, Justo AM. IRAMUTEQ: um software gratuito para análise de dados textuais. Temas em Psicologia. [Internet] 2013;21(2):513-18 [Acesso em 20 jan 2017]. Disponível: http://dx.doi.org/10.9788/TP2013.2-16.

19. Queirós PJP, Vidinha TSS, Filho AJA. Autocuidado: o contributo teórico de Orem para a disciplina e profissão de Enfermagem. Revista de Enfermagem Referência. [Internet] 2014;6(3):157-64 [Acesso em 15 mai 2017]. Disponível: http://dx.doi.org/10.12707/RIV14081.

20. Santos ACC. Autocuidado de mulheres grávidas com doença falciforme: construção de um protocolo de enfermagem [dissertação]. Salvador (BA): Universidade Federal da Bahia; 2015.

21. Victoria C, Knauth DR. Corpo, gênero e saúde: a contribuição da antropologia. In: Strey MN, Cabeda STL, organizadores. Corpos e subjetividade em exercício interdisciplinar. Porto Alegre: EDIPUCRS; 2004. p. 81-91. (Coleção Gênero e Contemporaneidade; 3)

22. Müller MI. Os médicos nunca me tocaram um dedo! Eu cansei daquele posto! A percepção das travestis quanto ao atendimento em saúde [especialização]. Porto Alegre (RS): Universidade Federal do Rio Grande do Sul; 2007. Disponível: http://hdl.handle.net/10183/12297.

23. Romano VF. As travestis no Programa Saúde da Família da Lapa. Saúde Soc. [Internet] 2008;7(2):211-19. [Acesso em 15 mai 2017]. Disponível: http://dx.doi.org/10.1590/S0104-12902008000200019.

24. Lacerda FKL. Autocuidado de mulheres com doença falciforme e úlcera de perna: Uma análise fundamentada na Teoria de Orem [dissertação]. Salvador (BA): Universidade Federal da Bahia; 2016. Disponível: https://repositorio.ufba. br/ri/handle/ri/20844. 